\title{
Desafíos de integrar la realidad aumentada en el entorno escolar mediante dispositivos móviles
}

\author{
Alex de Cassio Macedo \\ alex.macedo@escola.pr.gov.br \\ https://orcid.org/0000-0001-6620-7926 \\ Secretaria Estadual de Educação do Paraná (SEED-PR) \\ Universidade Federal do Paraná (UFPR) \\ Programa de Pós-graduação em Educação: Teoria e Prática de Ensino \\ Curitiba, Paraná, Brasil. \\ Anderson Roges Teixeira Góes \\ artgoes@ufpr.br \\ https://orcid.org/0000-0001-8572-3758 \\ Universidade Federal do Paraná (UFPR) \\ Programa de Pós-graduação em Educação: Teoria e Prática de Ensino \\ Programa de Pós-graduação em Educação em Ciências e em Matemática \\ Curitiba, Paraná, Brasil.
}

Recibido: 26/março/2021 Aceptado: 08/setembro/2021

\section{Resumen}

Este artículo tiene como objetivo discutir la integración de la tecnología digital de realidad aumentada como recurso en el aula, así como presentar los desafíos de su integración. Para ello, se desarrolló una investigación en las clases del profesor-investigador, sin necesidad de un laboratorio de computación o ningún otro espacio físico, es decir, la investigación se desarrolló en el entorno natural del salón de aula. En la investigación participaron 123 estudiantes de secundaria de cinco clases de un municipio de la costa de Paraná, Brasil. Fue parte de la metodología la creación de material didáctico impreso, asociado a la aplicación PolyhedRApp especialmente desarrollada para esta investigación. En las observaciones realizadas y en el análisis de los instrumentos de producción de datos, se verificaran los desafíos de la integración de la realidad aumentada, como la infraestructura y la falta de recursos en cuanto a equipamiento. Estas dificultades fueron mitigadas por la metodología y estrategias adoptadas, hecho confirmado por la evaluación de los participantes. Así, esta investigación aporta contribuciones a nuevas investigaciones sobre la integración de tecnologías digitales en el aula.

Palabras clave: Realidad aumentada; Geometría espacial; Dispositivos móviles; Educación matemática.

\section{Desafios da integração da realidade aumentada no ambiente escolar utilizando dispositivos móveis}

\section{Resumo}

Este trabalho tem o objetivo de discutir a integração da tecnologia digital de realidade aumentada como recurso em sala de aula, bem como apresentar os desafios de sua integração. Para isso, foi desenvolvida uma investigação em turmas do professor pesquisador, não sendo necessário laboratório de informática, tampouco outro espaço físico, ou seja, a investigação ocorreu no ambiente natural de sala de aula. Participaram da pesquisa 123 estudantes do Ensino Médio de cinco turmas de colégios de um município do litoral do Paraná, Brasil. Fez parte da metodologia a criação do material didático impresso, associado ao aplicativo PolyhedRApp, especialmente desenvolvido para esta pesquisa. Nas 
observações realizadas e nas análises dos instrumentos de produção de dados, verificaramse os desafios da integração da realidade aumentada, como infraestrutura, e a falta de recursos quanto a equipamentos. Essas dificuldades foram amenizadas pela metodologia e estratégias adotadas, fato comprovado pela avaliação dos participantes. Assim, esta pesquisa traz contribuições para novas investigações sobre a integração de tecnologias digitais em sala de aula.

Palavras-chave: Realidade aumentada; Geometria espacial; Dispositivos móveis; Educação matemática.

\title{
Challenges of integrating of augmented reality in the school environment using mobile devices
}

\begin{abstract}
This work aims to discuss the integration of digital technology augmented reality as a resource in the classroom and present the challenges of its integration. For this, an investigation was developed in classes of the teacher-researcher, not being necessary a laboratory of computer science and nor another physical space, that is to say, the investigation took place in the "natural" classroom environment. A total of 123 high school students from five colleges in a municipality on the coast of Paraná, participated in the study. The methodology involved the creation of didactic material, associated with the software PolyhedRApp, specially developed for this research. In the observations and analyzes of data collection instruments, we verified the challenges of the integration of augmented reality as infrastructure and the lack of resources such as equipment. These difficulties were mitigated by the methodology and strategies adopted, as evidenced by the participants' evaluation. Thus, this research brings contributions to new investigations on the integration of digital technologies in the classroom.
\end{abstract}

Keywords: Augmented reality; Spatial geometry; Mobile devices; Mathematical education.

\section{Introdução}

Desde os primórdios, a humanidade sobrevive e se mantém a partir da forma como resolve seus problemas, melhorando suas condições seja pela confecção de um artefato, seja pelo desenvolvimento de uma nova forma de produzir alimentos ou mesmo pela forma de se comunicar. Portanto, considerar que "tecnologia é a totalidade de coisas que a engenhosidade do cérebro humano conseguiu criar em todas as épocas, suas formas de uso, suas aplicações” (KENSKI, 2012, p. 23) parece ser uma definição abrangente e útil, principalmente no contexto escolar, no qual as tecnologias permeiam as práticas e podem ajudar em metodologias inovadoras e eficientes. Considerando esse contexto, Moran (2003) afirma que as tecnologias são os meios, os apoios e as ferramentas utilizadas para que os estudantes aprendam, bem como a forma como o professor organiza os grupos em salas ou em outros espaços. Também o giz que escreve no quadro é tecnologia para comunicação, sendo que uma boa organização da escrita facilita a aprendizagem, assim como o modo de 
olhar, de gesticular e de falar com os outros. O livro, a revista e o jornal são, igualmente, tecnologias fundamentais para a gestão e a aprendizagem, muitas vezes subpotencializadas, assim como o gravador, o retroprojetor, a televisão e o vídeo (MORAN, 2003).

Com o desenvolvimento da computação, da microeletrônica e da informática, algumas tecnologias deixaram de ser analógicas ou mecânicas e se tornaram digitais. Estas são produzidas ou desenvolvidas em circuitos eletrônicos baseados em lógica, que processam, armazenam e transmitem as informações em códigos binários por meio de programação, como os computadores, notebooks, smartphones, internet, videogames e outros. Esses aparelhos proporcionaram, nos últimos anos (MORAN, 2003; KENSKI, 2012), novas formas de comunicar, informar e adquirir conhecimento, contribuindo fundamentalmente na disseminação e no aprimoramento das tecnologias da informação e comunicação, que, por utilizarem o "digital”, passaram a ser designadas como Tecnologias Digitais da Informação e Comunicação (TDICs) ou, ainda, Tecnologias Digitais (TDs).

Para Kenski (2012), a TD é uma tecnologia de síntese que engloba aspectos da oralidade, da imagem e da escrita em novos contextos, rompendo as formas narrativas circulares e repetidas da oralidade. Isso traz um encaminhamento contínuo e sequencial da escrita e se apresenta como um fenômeno descontínuo e, ao mesmo tempo, dinâmico, aberto e veloz. Ela põe em segundo plano a estrutura serial e hierárquica na articulação dos conhecimentos, priorizando o estabelecimento de novas relações entre conteúdos, espaços, tempos e pessoas diferentes (KENSKI, 2012).

Essa nova forma de obter informações a partir das TDs se evidencia em hipertextos e hipermídias, que criam outra cultura e realidade informacional, presentes em redes sociais e ambientes colaborativos virtuais. Nesse contexto, a computação gráfica é o meio que desenvolve as inovações em games, simulações, vídeos e imagens. Uma concentração dessas características é presenciada no advento da realidade aumentada, que, apesar de sua característica imaterial, é materializada em aparelhos digitais de mídias domésticas, ou seja, está presente no cotidiano do ser humano e, assim sendo, deve ser parte do cotidiano também da escola. Mas simplesmente inserir as TDs no ambiente escolar não é suficiente para o processo de ensino e aprendizagem, é necessário integrá-las.

A integração de TDs na educação tem sido discutida amplamente na comunidade científica, porém muitas são as aplicações desse termo, uma vez que pode considerar diversos contextos, como o de investigar a integração de tecnologias na formação de professores (SERAFIM; SOUZA, 2011), na gestão educacional (MORAN, 2003), na 
elaboração de materiais didáticos que integram diferentes TDs (ALMEIDA, 2005) e a integração de tecnologias educacionais no ambiente sala de aula (COSTA; PRADO, 2015).

Posto isso, partimos da questão: como integrar a realidade aumentada no processo de ensino e aprendizagem da Matemática? Na busca por resposta para essa pergunta, foi desenvolvida uma intervenção em sala de aula de responsabilidade do professor pesquisador (primeiro autor deste texto), em uma escola pública do litoral do estado do Paraná, Brasil. Dentre os diversos aspectos observados durante a pesquisa, destaca-se o desafio de integrar a realidade aumentada em uma instituição pública, visto que os recursos financeiros e infraestrutura são insuficientes. Assim, o objetivo é discutir e apresentar os desafios enfrentados na integração dessa TD em sala de aula, mostrando as maneiras como tais desafios foram solucionados, contribuindo com a comunidade acadêmica e o professorado ao utilizar tal recurso.

A fase inicial da integração das TDs no ambiente escolar é a inserção de tais recursos; no entanto, apenas inserir não é suficiente, visto que dessa maneira ocorrem usos isolados deles. É necessário que as TDs "passem por despercebidas" no ambiente escolar, como o lápis, que é uma tecnologia educacional (GÓES; GÓES, 2018) e muitos não o consideram como tal, pois já está integrado ao ambiente escolar. Para essa discussão, este texto está organizado em cinco seções, incluindo esta introdução. Na próxima seção, é discutida a integração das TDs em sala de aula e a realidade aumentada, apontando conceituações e o referencial teórico que auxiliam no debate sobre os desafios da integração das TDs apresentadas na seção quatro. A terceira seção apresenta a metodologia da pesquisa, indicando os encaminhamentos da intervenção e os materiais utilizados. Por fim, na quinta seção são realizadas as considerações apontadas por esta pesquisa.

\section{A integração das tecnologias digitais em sala de aula - conceituação}

Integrar é, conforme o Dicionário Aurélio (FERREIRA, 1999), tornar inteiro; completar; integralizar; fazer parte de; juntar; incorporar; tornar-se parte integrante; incorporar-se. Nesse sentido, a integração pode ser entendida como o "ato de integrar" e, portanto, é necessário definir aquilo que será integrado, o elemento integrante e o conjunto já estabelecido. Assim, para que ocorra o processo de integração, espera-se que integrante e integrado formem um todo estabilizado ou integral, sendo necessário um agente que realize essa ação, o integrador.

Todo processo de integração demanda necessidade e/ou interesse, que pode ser emanado de ambas as partes (integrante e integrado). As consequências acarretam por vezes 
mudanças no integrante e no integrado, de maneira a afetar o conjunto resultante do processo em que tomar ciência de sua ocorrência é reconhecer e compreender esses elementos de maneira clara e articulada.

É preciso também definir o termo "investigação", que, segundo o mesmo dicionário, é o ato de investigar (FERREIRA, 1999), ou seja, seguir vestígios; pesquisar; examinar com atenção. Nessa ação, o investigador (agente do ato) observa, pesquisa e examina algo em alguém ou em alguma coisa. Portanto, há distintamente três elementos da investigação: o investigador, o investigado e igualmente um "motivo", um questionamento a ser respondido com a investigação. Contudo, para que o processo de investigação ocorra, esses elementos não são suficientes, havendo a necessidade de metodologia que conduza às ações adequadas para tal, levando em consideração o investigado e o questionamento motivador da investigação.

No campo educacional, a investigação pressupõe um trabalho específico, que emana de uma postura própria do pesquisador/investigador, ganhando visibilidade, na atualidade, o papel do professor pesquisador. Para Lüdke (2001), um professor pesquisador reivindicava para si a mesma situação do artista, ensaiando com seus diferentes materiais as melhores soluções para os problemas de criação e as experimentando em cada sala de aula, como num laboratório, para atingir os estudantes, aprimorando o processo de ensino e aprendizagem. Esse aprimoramento no processo acontece com a inclusão integrada de novos recursos e possibilidades. Dessa forma, investigar a integração de TDs em sala de aula pressupõe, a partir do já exposto, esclarecer os elementos que compõem a investigação e a integração, acreditando que a definição de cada um deles proporciona clareza e objetividade às ações necessárias à pesquisa.

Diversos autores discutem a integração da tecnologia no contexto educacional (MORAN, 2003; BITTAR, 2010; KESKI, 2012; COSTA; PRADO, 2015; GÓES; GÓES, 2018), afirmando a necessidade e a importância de diversos recursos, digitais ou não, na potencialização de metodologias de ensino e como mediadores dos processos de aprendizagem nos dias atuais. Apenas inserir uma TD no ambiente escolar não é suficiente, sendo preciso integrá-la, pois "integrar um novo instrumento [TD] em sala de aula, implica mudanças pedagógicas, mudanças do ponto de vista da visão de ensino, que deve ser estudada e considerada pelos professores. (BITTAR, 2010, p. 220).

Nesse sentido, o que significa integração?

O elemento integrante do processo, ou seja, aquele que deve ser inserido como elemento novo, é aqui denominado recurso tecnológico. Tal recurso pode ser um telefone 
móvel, computador, televisor e outros dispositivos que todos os dias surgem e que de alguma maneira ainda não são rotineiros na prática escolar. Portanto, os recursos tecnológicos são tomados aqui em seu sentido mais amplo, pois o termo "tecnologia" é empregado atualmente, no senso comum, como sendo inovações e novidades provenientes da microeletrônica, indústria, computação e outras advindas muitas vezes das ciências aplicadas, porém essa forma de compreender tecnologia é muito restrita e desconsidera a construção histórica e social desse conceito (GÓES; GÓES, 2018).

O elemento integrante investigado nesta pesquisa é a realidade aumentada em dispositivos móveis. Tal tecnologia teve início em meados da década de 1960, porém somente em 1980 o primeiro uso foi registrado pelas Forças Armadas americanas na construção de um simulador de avião que, com visão óptica direta, misturando elementos virtuais com o ambiente real do usuário (RIBEIRO; ZORZAL, 2011), é um conceito que deriva da realidade virtual e teve sua origem na computação gráfica.

Para Azuma (1997), os sistemas de realidade aumentada são constituídos por três características básicas: combinação do real com o virtual, interação em tempo real e imagem tridimensional. A realidade aumentada reúne técnicas computacionais que, a partir de um dispositivo tecnológico, geram, posicionam e mostram objetos virtuais integrados a um cenário real, mantendo o senso de presença no mundo físico. Esse mecanismo enfatiza a qualidade das imagens e a interação do usuário com esses objetos em tempo real.

Nesse tipo de interação, o usuário pode se mover livremente em torno do objeto, visualizando e explorando todas as suas vistas (TORI; KIRNER; SISCOUTTO, 2006). Na atualidade, devido aos diversos recursos que proporcionam mobilidade em seu uso, como tablets e smartphones, é denominada Realidade Aumentada Móvel (RAM), proporcionando visão indireta para geração de cenas de maneira não imersiva.

O funcionamento desse sistema constitui-se na apresentação de um marcador para a captura de imagem da câmera. Em seguida, o sistema, por meio de um aplicativo, detecta e rastreia o marcador, projetando os objetos tridimensionais ou qualquer outra mídia, visualizados simultaneamente pelo usuário, conforme esquema apresentado FIGURA 1.

Figura 1 - Funcionamento de um aplicativo em RAM 


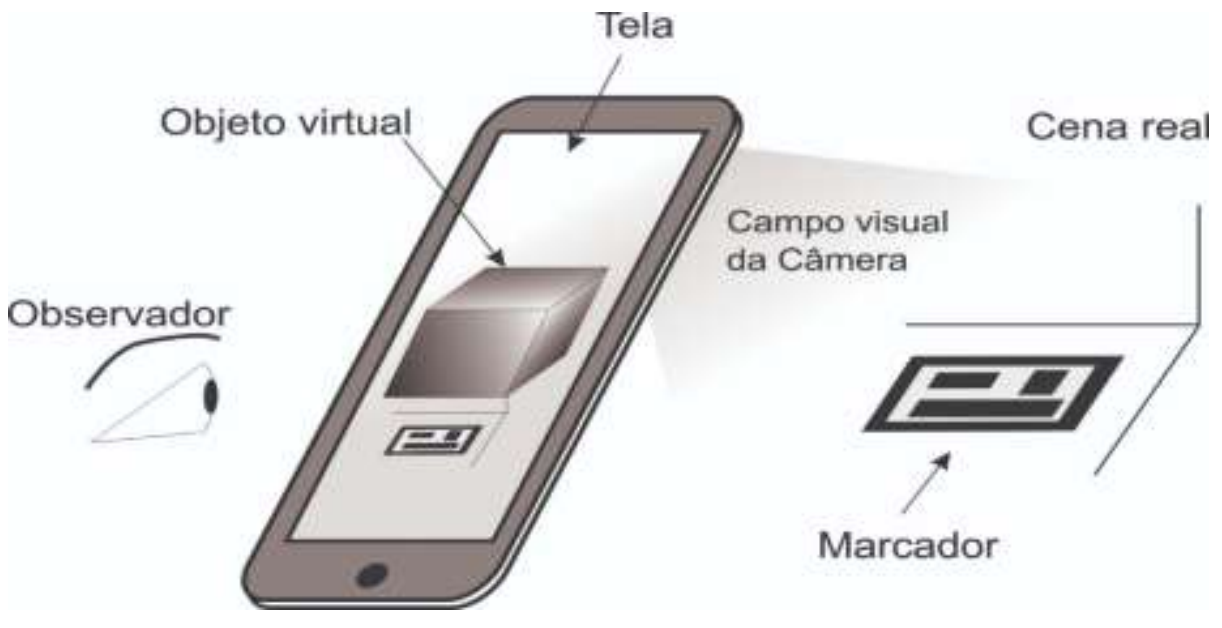

Fonte: Os autores, 2020.

Os marcadores são imagens "traduzidas" em tempo real a partir do reconhecimento de padrões e utilizadas como pontos de referência para estabelecer as posições, orientações e escalas de objetos virtuais no ambiente real por meio de visão computacional. Para Billinghurst (2002), as aplicações de RAM que se utilizam dessa característica são implementadas considerando a capacidade de usar objetos físicos para manipular as informações virtuais de maneira intuitiva. Nessas aplicações, pessoas sem grande conhecimento de computação podem ter uma experiência de interação bastante rica, pois não há mouse ou teclado para serem operacionalizados. Isso habilita todas as pessoas, desde educandos mais jovens àqueles com mais idade, a ter contato e autonomia com a tecnologia na participação de uma rica experiência educacional.

O conjunto integrado nesta pesquisa é a sala de aula, não apenas como um ambiente físico, mas como uma metáfora de todo o processo de ensino e aprendizagem. Dessa forma, considera-se sala de aula todos os elementos que a constituem: estudantes, ambiente, material didático, professor e estrutura institucional. Talvez esse seja o elemento da integração mais difícil de definir, uma vez que as variantes possíveis em sua constituição são quase infinitas. Mesmo que, na educação formal, a sala de aula seja o "lugar" onde ocorre a maior parte do processo de aprendizagem, é impossível determinar os momentos e lugares onde a aprendizagem ocorre, pois grande parte de nosso conhecimento advém também de situações extraescolares. Dar sentido aos conceitos a ser compreendidos na sala de aula é função do professor, que deve propor maneiras e caminhos para que o estudante alcance seus objetivos, discutindo, revendo e criando situações de aprendizagem.

É nesse contexto que os recursos tecnológicos devem ser instrumentos para mediar essas relações, fornecendo novas maneiras e abordagens aos problemas e situações de aprendizagem, facilitando a comunicação e ampliando as possibilidades de interação entre 
estudante-professor-conhecimento-(e agora)mundo. É necessário perceber que a integração das TDs em sala de aula não é uma tarefa fácil, pois "implica na necessidade da construção de novos conhecimentos pelo professor, de modo a se apropriar das tecnologias digitais e integrá-las aos conteúdos curriculares" (COSTA; PRADO, 2015, p. 4). As TDs proporcionam ao professor desenvolver conhecimentos que o ajudem a "raciocinar com", "criar com" e "ensinar com" tecnologia - ensinar, não apenas inserindo-as na sala de aula, mas integrando-as e explorando adequadamente o que elas potencializam (COSTA; PRADO, 2015).

O esquema a seguir (FIGURA 2) apresenta os conceitos abordados nesta seção, definindo tais conceitos e, ao mesmo tempo, indicando os elementos do ambiente educacional.

Figura 2 - Sistema (a) antes e (b) depois da integração de recursos tecnológicos e as possíveis interações
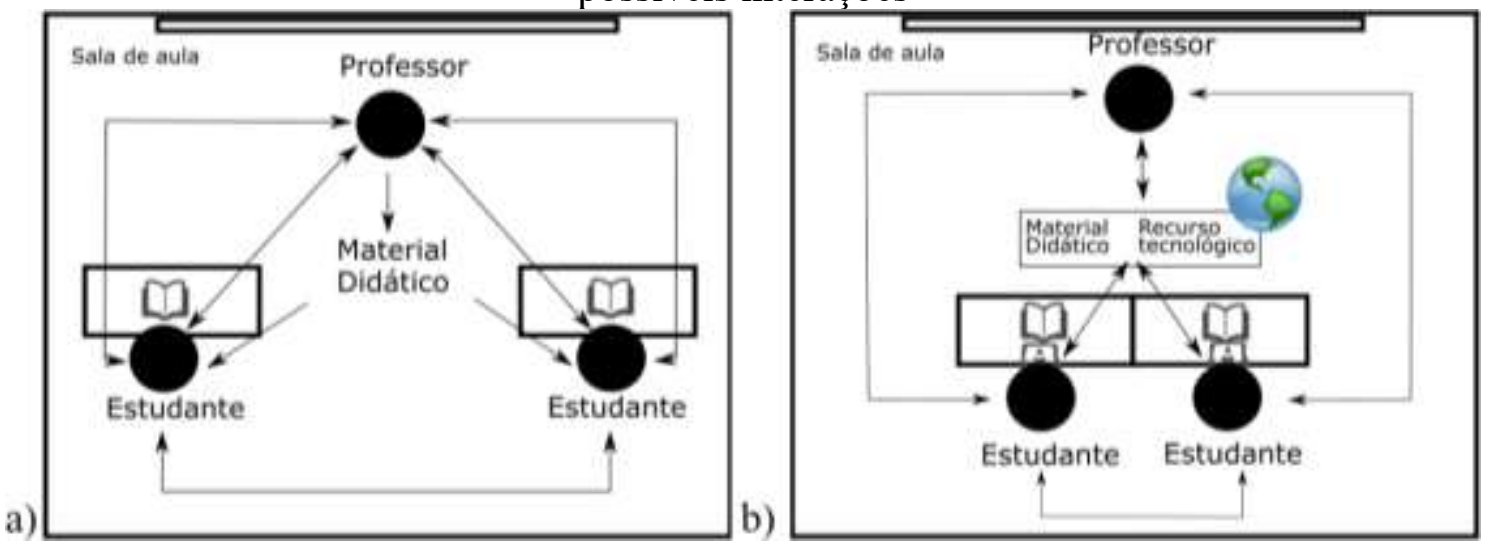

Fonte: Os autores, 2020.

No sistema (Figura 2a) sem recurso tecnológico integrado, o ambiente de sala de aula se mantém no material didático criado (ou não) pelo professor, que serve de interface para o conteúdo abordado; as interações entre professor-estudante e entre estudantes se limitam à experiência de cada um, podendo haver compartilhamento de ideias, mas sempre centrado no que foi elaborado pelo professor. Ainda, a infraestrutura necessária é clássica, composta de quatro de giz, carteiras, livros e outros materiais escolares. Podemos dizer que esse é o modelo tradicional, aqui considerado sistema integrado preexistente.

O recurso tecnológico, como elemento integrador, modifica o sistema descrito anteriormente, agregando possibilidades e interações. Como apresentado na Figura 2b, o sistema integrado com o recurso tecnológico possibilita interações e as intensifica, uma vez que se pode elaborar um material didático dinâmico em que cada elemento colabora com a construção do conhecimento e do aprendizado coletivo. Isso ocorre, sobretudo, no acesso à 
internet, que permite a pesquisa, tornando quase infinitas as possibilidades de encaminhamento de um mesmo assunto. O compartilhamento de ideias e informações pode ser intenso, sem o risco de perder a originalidade individual, haja vista os recursos de registros pessoais de cada estudante. A infraestrutura é mais complexa, exigindo acesso a equipamentos de TDs para todos os estudantes e professor, bem como uma estrutura elétrica e organizacional para tal.

Com a RAM, é possível abordar situações extras no aprendizado da geometria pela visualização de uma grande quantidade de sólidos e possibilidades virtuais de secções, planificações e outras interações que seriam inviáveis com materiais concretos, dada a logística de transporte e espaço físico.

Expostas nossas considerações sobre a integração das TDs no ambiente escolar, a próxima seção discute a metodologia de nossa pesquisa.

\section{A pesquisa em sala de aula}

A pesquisa realizada possui abordagem qualitativa e, por meio de uma intervenção pedagógica, apoiada por uma sequência de atividades, investiga a integração da realidade aumentada em dispositivos móveis no processo de ensino e aprendizagem de geometria espacial no Ensino Médio, destacando os desafios da integração das TDs.

Como instrumento de coleta de dados, foi realizado um levantamento informal anterior ao início da pesquisa, com a finalidade de verificar quantos estudantes possuíam smartphone. Posteriormente, foi aplicado um questionário inicial on-line (via Google Forms) para levantamento do perfil educacional e tecnológico dos participantes.

Após a intervenção com a sequência de atividades, foi aplicado um questionário, em material impresso, no último encontro, para avaliar, a partir da perspectiva dos participantes, o aceite do material didático impresso e da tecnologia utilizada (realidade aumentada). Ainda, esse instrumento teve a finalidade de analisar aspectos pedagógicos, como qualidade do encaminhamento metodológico e interações entre estudantes e professor, bem como as dificuldades encontradas, fossem elas de infraestrutura ou didática.

A sequência de atividades consistiu em seis encontros de cem minutos em cada uma das turmas e, dentre os recursos utilizados, empregou-se um material didático (impresso) associado a um aplicativo desenvolvido para esta pesquisa. A necessidade de criação de um aplicativo próprio para a pesquisa surgiu da ausência de um aplicativo existente, gratuito e em língua portuguesa que atendesse aos interesses da investigação proposta. $\mathrm{O}$ nome dado a ele (PolyhedRApp) é composto por elementos que integram justamente sua concepção: 
Polyhed faz referência à palavra "poliedro" em grego e RA é a sigla correspondente à tecnologia utilizada (realidade aumentada), comum em aplicações para dispositivos móveis.

O material didático impresso foi elaborado com base nas diretrizes curriculares do estado do Paraná e nos livros didáticos fornecidos pelo Programa Nacional do Livro Didático (PNLD), contendo marcadores (exemplo na FIGURA 3) com os quais o aplicativo interage, a fim de possibilitar a visualização do objeto virtual.

Figura 3 - (a) Imagem do marcador; (b) tela do aplicativo com inserção do objeto virtual na cena

a)

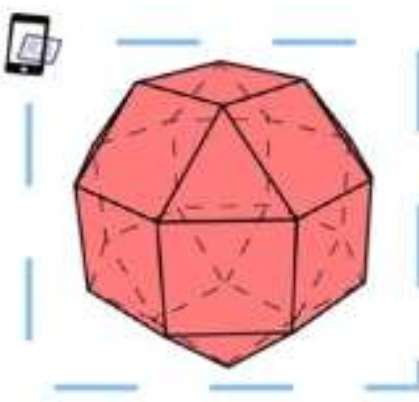

b)

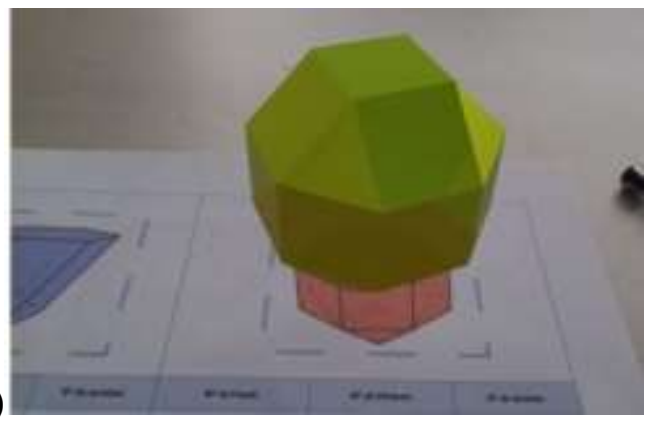

Fonte: Os autores, 2020.

Os encontros da intervenção abordaram os conteúdos matemáticos

encaminhamentos indicados no Quadro 1, em forma sequencial.

Quadro 1 - Conteúdos matemáticos e encaminhamentos metodológicos por encontro.

\begin{tabular}{|c|c|}
\hline & \\
\hline $\begin{array}{l}\text { Objetivos: Apresentação, leitura e } \\
\text { entrega dos termos de aceite para } \\
\text { participação na pesquisa; divulgação do } \\
\text { link para instalação do aplicativo } \\
\text { educacional e orientações de } \\
\text { configurações; e aplicação do d } \\
\text { questionário inicial. }\end{array}$ & $\begin{array}{l}\text { Inicialmente, foram apresentados a sequência de atividades, o } \\
\text { funcionamento do aplicativo e os esclarecimentos acerca da } \\
\text { pesquisa que seria realizada. Houve a leitura e explicação dos } \\
\text { termos (TALE e TCL), com abertura para perguntas e } \\
\text { proposições. Em seguida, os estudantes responderam ao } \\
\text { questionário inicial via Google Forms no laboratório de } \\
\text { informática. }\end{array}$ \\
\hline
\end{tabular}
$\mathbf{2}^{\mathbf{o}}$ encontro: Geometria espacial - conceitos iniciais

\begin{tabular}{|c|c|}
\hline $\begin{array}{l}\text { Objetivos: Diferenciar os conceitos de } \\
\text { tridimensional e bidimensional; } \\
\text { conceituar e diferenciar poliedros de } \\
\text { corpos redondos. }\end{array}$ & $\begin{array}{l}\text { Os participantes foram organizados em duplas ou trios } \\
\text { (conforme a disposição dos dispositivos móveis) e seguiram } \\
\text { o roteiro de aprendizagem proposto pelo material impresso; } \\
\text { manuseando o aplicativo, exploraram os conceitos e } \\
\text { resolveram as atividades. Ao final, ocorreu uma } \\
\text { sistematização, com o professor convidando os participantes } \\
\text { a compartilhar seus registros, criando uma definição geral } \\
\text { com toda a classe, sobre os conceitos estudados. Todos os } \\
\text { participantes entregaram suas folhas de atividades para } \\
\text { posterior avaliação e registros. }\end{array}$ \\
\hline \multicolumn{2}{|l|}{$3^{\circ}$ encontro: Poliedros } \\
\hline $\begin{array}{l}\text { Objetivos: Definir e classificar os } \\
\text { poliedros; reconhecer os elementos de um }\end{array}$ & $\begin{array}{l}\text { Em duplas ou trios, os participantes, por meio de realidade } \\
\text { aumentada, assistiram a uma animação relativa à definição de } \\
\text { poliedros; em seguida, discutiram sobre a nomeação dos }\end{array}$ \\
\hline
\end{tabular}




\begin{tabular}{|c|c|}
\hline $\begin{array}{l}\text { poliedro; reconhecer em objetos reais } \\
\text { formas poliédricas. }\end{array}$ & $\begin{array}{l}\text { poliedros e, por fim, diferenciaram em convexos e não } \\
\text { convexos. Durante todo o roteiro de aprendizagem, as } \\
\text { atividades cobraram dos participantes conjecturas e } \\
\text { definições que foram lidas e sistematizadas ao final do } \\
\text { encontro. }\end{array}$ \\
\hline \multicolumn{2}{|l|}{$4^{\circ}$ encontro: Poliedros regulares } \\
\hline $\begin{array}{l}\text { Objetivos: Reconhecer e diferenciar os } \\
\text { poliedros regulares; articular os } \\
\text { conhecimentos matemáticos com a } \\
\text { história da filosofia por meio dos } \\
\text { poliedros platônicos; aplicar a relação de } \\
\text { Euler em poliedros. }\end{array}$ & $\begin{array}{l}\text { Por meio de uma articulação entre Matemática e Filosofia, } \\
\text { foram definidos os poliedros regulares e sólidos platônicos, } \\
\text { identificando suas propriedades e características. As } \\
\text { atividades promoveram as conjecturas necessárias para que os } \\
\text { estudantes compreendessem poliedros regulares, bem como, } \\
\text { a partir deles, discutissem a relação entre seus elementos, } \\
\text { levando ao conhecimento da relação de Euler e à } \\
\text { generalização desse conceito para outros poliedros. }\end{array}$ \\
\hline \multicolumn{2}{|c|}{$\mathbf{5}^{\circ}$ encontro: Poliedros convexos - prismas e pirâmides } \\
\hline $\begin{array}{l}\text { Objetivos: Definir e classificar os } \\
\text { prismas; reconhecer as propriedades e } \\
\text { elementos de um prisma; reconhecer o } \\
\text { cubo e o paralelepípedo como prismas } \\
\text { especiais; explorar as relações métricas do } \\
\text { cubo, do paralelepípedo e de um prisma } \\
\text { qualquer; definir e classificar as } \\
\text { pirâmides; reconhecer as propriedades e } \\
\text { elementos de uma pirâmide; reconhecer o } \\
\text { tetraedro como uma pirâmide especial; } \\
\text { explorar as relações métricas da pirâmide. }\end{array}$ & $\begin{array}{l}\text { Os participantes foram organizados em grupos (com três ou } \\
\text { quatro) e seguiram o roteiro de aprendizagem proposto pelo } \\
\text { material impresso; manuseando o aplicativo, exploraram os } \\
\text { conceitos e resolveram as atividades. Ao final, ocorreu uma } \\
\text { sistematização, com o professor convidando os participantes } \\
\text { a compartilhar seus registros, criando uma definição geral } \\
\text { com toda a classe. Todos entregaram suas folhas de atividades } \\
\text { para posterior avaliação e registros. }\end{array}$ \\
\hline \multicolumn{2}{|l|}{$6^{\circ}$ encontro: Questionário final } \\
\hline $\begin{array}{l}\text { Objetivo: Aplicação do questionário } \\
\text { final. }\end{array}$ & $\begin{array}{l}\text { Os estudantes foram convidados a responder a um } \\
\text { questionário impresso após um bate-papo sobre a experiência } \\
\text { vivenciada nos cinco encontros anteriores. }\end{array}$ \\
\hline
\end{tabular}

Fonte: Os Autores (2020).

A investigação buscou levantar aspectos observáveis da integração da realidade aumentada em um ambiente "natural" de sala de aula, uma vez que o professor regente das turmas era o próprio pesquisador (primeiro autor deste texto) (LÜDKE, 2001).

Os dispositivos móveis pertenciam aos estudantes e não foi necessário um laboratório de informática equipado, tampouco outro espaço físico, ocorrendo a integração deles no ambiente escolar (KENSKI, 2012; GÓES; GÓES, 2018). Foram realizados registros em áudio e vídeo e a aplicação de questionários para obtenção dos dados. Por se tratar de uma pesquisa envolvendo adolescentes, cujos dados foram obtidos por meio de registro audiovisual, houve a necessidade de submeter a pesquisa à análise e aprovação do Comitê de Ética em Pesquisa da Universidade Federal do Paraná e da Superintendência da Secretaria de Educação do Paraná, recebendo autorização para implementar a pesquisa em sala de aula. A pesquisa foi iniciada após a aprovação em Comitê de Ética.

Do total de 123 estudantes das cinco turmas, 70 aceitaram fornecer dados e participar da pesquisa, assinando os termos de aceite - tanto os participantes quanto seus responsáveis, quando necessários. Outros 52 aceitaram trabalhar com o material, mas não participar 
fornecendo dados e registros audiovisuais de suas atividades em sala; e uma estudante não aceitou nem o material nem o uso de smartphone como recurso pedagógico.

Ressalta-se que, na apresentação da pesquisa e nos documentos de concordância e direito de uso imagem, foram evidenciados a intenção dos registros e o sigilo pleno do material gravado exigido pela ética em pesquisa. No entanto, a não concordância em participar da pesquisa ocorreu devido à vergonha em serem gravados ou ao medo de serem avaliados (externamente à pesquisa) pelo registro. Durante os seis encontros, não foram registrados quaisquer problemas quanto à interação entre estudantes e professor, bem como entre os estudantes e o ambiente de aprendizagem.

Os participantes eram de cinco turmas do Ensino Médio, sendo três do Ensino Médio regular (uma $2^{\mathrm{a}}$ série do período matutino e duas $3^{\mathrm{a}}$ séries do período noturno) e duas do Ensino Médio integrado de formação de docentes (período matutino), lotadas em duas escolas da região litorânea do Paraná, locais de atuação do professor pesquisador.

Quanto à faixa etária dos participantes, nas turmas do período matutino, a maioria tinha entre 15 e 19 anos. Já nas turmas do período noturno, todos os estudantes, sendo a maioria composta por trabalhadores e donas de casa, possuíam idade igual ou maior que 19 anos.

Para melhor apresentar os resultados obtidos durante a coleta de dados e buscando preservar a identidade dos participantes, foi utilizado um sistema de codificação para as turmas e participantes. Cada turma foi identificada por uma letra maiúscula do alfabeto (A, B, C, D e E), enquanto os estudantes receberam uma codificação indicando a turma e um número associado à ordem de envio do questionário inicial (via Google Forms), ou seja, para um participante da turma A, sua codificação foi PA\#\#, em que \#\# indica a ordem de envio do questionário. Em relação ao professor pesquisador, esse foi identificado como PP.

$\mathrm{Na}$ próxima seção, são apresentados os desafios na integração da realidade aumentada nas aulas de geometria espacial do Ensino Médio. Os dados foram produzidos por meio de questionários, áudio e vídeo, bem como das observações registradas em instrumento próprio (caderno de anotações) do professor pesquisador. Assim, nas discussões a seguir, realizamos uma triangulação entre os dados produzidos pelos instrumentos citados, as observações dos pesquisadores e o referencial teórico.

\section{Desafios da integração da realidade aumentada móvel}


Os desafios enfrentados na integração da realidade aumentada no ambiente escolar são apresentados como forma de evidenciar as dificuldades vivenciadas pelo professor pesquisador, demonstrando os caminhos seguidos para superá-los.

As investigações que ocorrem na escola esbarram, sobretudo, em questões naturais, como a cultura trazida pelos estudantes e suas ideias sobre educação, além da compreensão por parte da comunidade sobre a importância de participação em pesquisas científicas. Esse fato foi o primeiro desafio vivenciado nesta pesquisa, pois, como comentado na seção anterior, nem todos os estudantes aceitaram ou foram autorizados a participar da pesquisa. No entanto, cabe ressaltar que o uso de dispositivos móveis é parte integrante dos recursos utilizados pelo professor pesquisador em seu cotidiano em sala de aula; mesmo assim, uma das estudantes não concordou em utilizar os materiais produzidos para a pesquisa.

Como esta pesquisa investigou uma ação do professor regente da turma (LÜDKE, 2001), tais materiais são os instrumentos que o docente julga ser os mais adequados para utilização em sala de aula na abordagem dos conceitos de geometria espacial. Para atender à estudante que não utiliza smartphone, foram propostos materiais alternativos, como atividades do livro didático e manuseio de materiais concretos disponíveis no colégio (sólidos acrílicos), mantendo sempre o atendimento por parte do professor quando solicitado. Isso demonstra a versatilidade do professor pesquisador, que precisa estar atento às diversas culturas presentes no ambiente escolar, proporcionando metodologias e recursos alternativos. Como afirmam Moran (2003) e Kenski (2012), quando o tema é tecnologia, somam-se aos desafios de sua integração os referentes ao aceite e capacidade de mudança que cada uma das pessoas envolvidas deve assumir.

Mesmo com o evidente aumento nas pesquisas que envolvem TDs na educação e os resultados positivos apontados por elas, ainda se percebe que a quantidade de escolas equipadas com computadores ou dispositivos móveis para atender individualmente a cada estudante é insuficiente, sobretudo nas escolas públicas brasileiras, que possuem insuficiência em recursos e infraestrutura (DUNCAN, 2014). Esse foi o segundo desafio nas instituições de ensino em que esta pesquisa foi realizada.

Nos dois colégios que participaram da pesquisa, apesar de possuírem laboratório de informática, a quantidade de computadores é inferior ao número de estudantes de cada turma e nenhum dos laboratórios é equipado com tablets, notebook ou outros equipamentos móveis. Essa dificuldade poderia até não existir se a realidade de infraestrutura das escolas públicas fosse outra. A solução para enfrentar esse desafio foi utilizar o dispositivo móvel (smartphone) pessoal; antes que a proposta fosse comunicada aos participantes, um 
levantamento informal nas turmas foi realizado pelo professor pesquisador para que posteriormente pudessem ser convidadas a participar da investigação.

Nesse levantamento, foi possível averiguar que, dos 123 participantes, 88 tinham smartphone. Destes, 85 levavam o equipamento para escola e 78 possuíam smartphone com sistema operacional Android, versão compatível com o aplicativo em realidade aumentada desenvolvido para esta pesquisa. Esses dados mostram que, por mais que haja um mundo repleto de TDs, sua aquisição não é acessível à totalidade da população, nem mesmo pelos participantes que já trabalham e não dependem financeiramente de outros membros da família (KENSKI, 2012; GÓES; GÓES, 2018).

Para solucionar esse desafio, a pesquisa foi realizada em grupos de estudantes, o que gerou motivação e socialização na aprendizagem, fato que pode ser verificado no diálogo a seguir, em que a participante PA12 questionou o professor pesquisador sobre o tamanho do quadro da Monalisa, apresentada na atividade sobre imagem bidimensional e tridimensional na arte onde, em que aparecem lado a lado o quadro da Monalisa e a estátua de Davi, o que provocou discussão com sua dupla (participante PA07):

PA12: Nossa! Acho que o tamanho da Monalisa tá errado! PA07: Por quê?

PA12: Professor, esta imagem está desproporcional, não é?

PP: Na verdade, não tenho certeza, você se refere à proporção entre o quadro e a estátua?

PA12: Sim!

Após pesquisas utilizando a internet, supervisionadas pelo professor pesquisador, os participantes concluíram:

PA07: Aqui ó! A Monalisa tem 77 centímetros por 53 centímetros!

PA12: E a estátua?

PA07: Como é o nome da estátua?

PA12: Davi! De Michelangelo!

PA07: Tem 517 centímetros de altura e uma base de 199 centímetros de diâmetro.

PA12: Falei! Ela parece maior do que é, né professor?!

PA07: Será?

PP: Só verificando quantas vezes a estátua é mais alta que o quadro, na realidade e na imagem $3 \mathrm{D}$ !

Esses participantes realizaram uma breve discussão analisando as dimensões, o que despertou a atenção dos demais. Uma solução foi apresentada, utilizando uma régua para medir as imagens e anotando as dimensões encontradas. Na continuidade do diálogo: 
PA07: Professor... a (PA12) me ajudou a segurar o celular e então medi com a régua a altura da Monalisa e da estátua!

PA12: Deu 1,5 centímetros e quase 10 centímetros o Davi.

PP: E aí, qual foi a conclusão

PA12: Agora tem que dividir? Para saber o quanto um é maior que outro?

PP: Sim!

PA07: Nas medidas aqui da internet ficou...517 dividido por $77 \ldots$ deu 6,714 , e um monte de número [pausa para execução de outro cálculo] e 10 dividido por 1,5 deu 6,6666. Como é? Dízima!

PA12: Então ficou 6,7 na imagem real e 6,6 na imagem gerada no aplicativo! O que significa?

PP: Que a estátua é aproximadamente 6,7 vezes maior que o quadro. E a imagem gerada da Realidade Aumenta é 6,6 vezes maior.

PA07: Dá para dizer que é quase a mesma proporção, né?!

PA12: Mas eu não estava toda errada. Na imagem o quadro é um pouquinho maior que na verdade.

Os questionamentos gerados e a busca de saberes pelos participantes são aspectos motivacionais gerados pela realidade aumentada (NOVAL, 2013; COLPANI, 2015), assim como o aumento do interesse dos participantes pelo conteúdo mediado (MAIA, 2014; MACEDO, SILVA, BURIOL, 2016) e a possibilidade de interações entre os membros da equipe, enriquecendo um ambiente de trabalho colaborativo de reflexões e conjecturas (OLIVEIRA, 2016).

Outro desafio enfrentado foi a permissão para uso de telefones móveis no ambiente escolar. Apesar de essa tecnologia fazer parte do cotidiano de muitos estudantes, como confirmado pelos dados já apresentados, e da sociedade em geral, seu uso no ambiente escolar é muitas vezes proibido. Essa tecnologia, se potencializada em uso no ambiente escolar, auxilia o professor e estudantes na solução de problemas que surgem no rico movimento de sala de aula (GÓES; GÓES, 2018), como demonstrado nos diálogos anteriores sobre a proporção entre o quadro da Monalisa e a estátua de Davi, em que se fez necessária a utilização de pesquisa na internet.

Como a intervenção surgiu de uma pesquisa aprovada em Comitê de Ética, contendo planejamento específico para utilizar os dispositivos móveis, respaldado em lei estadual que permite seu uso em sala de aula, houve autorização pela gestão escolar para fazer tal aplicação. Cabe ressaltar que o uso desses equipamentos é massivamente incentivado e investigado na comunidade acadêmica e que, devido ao movimento da sala de aula, entendese que tal autorização deve ser plena e sem burocracias, sendo de responsabilidade do professor a decisão sobre seu uso ou não em sala de aula, pois é ele que vivencia suas práxis e sabe dos recursos de que necessita (LÜDKE; CRUZ; BOING, 2009).

Outro desafio vivenciado ocorreu no momento da instalação do aplicativo PolyhedRApp. Alguns smartphones não tinham espaço na memória para a instalação e um 
modelo específico de aparelho não aceitava instalação de fonte externa (ou fonte desconhecida). No primeiro caso, os próprios estudantes se comprometeram em fazer backup de suas mídias (fotos e músicas) para que pudessem realizar a instalação no próximo encontro. Já a segunda situação exigiu uma pesquisa para verificar se o modelo de smartphone em questão necessitava de algum gerenciador de arquivos instalado. Tais fatos são situações vivenciadas por aqueles que realizam pesquisa em educação, sobretudo quando se propõem a utilizar equipamentos que as instituições de ensino não possuem, gerando uma diversidade de configurações dos recursos (DUNCAN, 2014).

Outros desafios, seguindo os apontamentos de Duncan (2014), foram percebidos logo no segundo encontro e perduraram por toda a aplicação da pesquisa. Por exemplo, nas salas de aula utilizadas, em prédios relativamente antigos, é comum ter no máximo duas tomadas de energia elétrica; assim, mesmo solicitando aos participantes que mantivessem carregados seus aparelhos, alguns tiveram as baterias esgotadas durante o encontro (visto que a realidade aumentada mantém a tela e o processamento ativos durante todo o tempo de uso, fazendo com que o aparelho consuma mais energia). Por isso, foi necessário que uma extensão elétrica fizesse parte do material do professor pesquisador.

Ainda, nas instituições em que a pesquisa foi realizada, o sinal da internet é baixo e muitos participantes tiveram de instalar o aplicativo utilizando a rede de suas residências. Em um dos colégios, o sinal da internet não é liberado aos estudantes, tendo sido necessário que o professor pesquisador realizasse o login em cada equipamento. Uma alternativa para realizar a instalação foi no modo off-line, com a disponibilização do arquivo de instalação via computador (transferência de dados via cabo) e pen drive; em alguns casos, os próprios estudantes transmitiram via Bluetooth.

Esses desafios são exemplos de mazelas que acometem a própria escola pública, incluindo a falta de estrutura e de boas políticas públicas, turmas lotadas, falta de professores, formação e capacitação dos profissionais da educação, entre outros (LÜDKE; CRUZ; BOING, 2009).

Mesmo diante dos contextos apresentados nesta seção, as medidas adotadas pelo professor pesquisador ao se deparar com esses desafios, como também a metodologia utilizada para a integração do dispositivo móvel em sala de aula, foram suficientes para que os participantes tivessem uma visão positiva com relação ao uso dessa realidade aumentada no ensino e aprendizagem de geometria espacial.

No questionário aplicado ao final da pesquisa, $74 \%$ dos participantes que possuíam smartphone não se sentiram prejudicados pelo fato de terem de compartilhá-lo com outros 
colegas. Por sua vez, 70\% dos participantes que não possuíam smartphone não se sentiram prejudicados na aprendizagem devido a isso. Esses dados demonstram que o compartilhamento de informações por meio do trabalho em grupo auxilia no convívio social, bem como na aprendizagem.

\footnotetext{
O uso da TIC com vistas à criação de uma rede de conhecimentos favorece a democratização do acesso à informação, a troca de informações e experiências, a compreensão crítica da realidade e o desenvolvimento humano, social, cultural e educacional. Tudo isso poderá levar à criação de uma sociedade mais justa e igualitária (ALMEIDA, 2005, p. 110).
}

$\mathrm{Na}$ busca por soluções para os problemas que surgiram (falta de recurso e improvisos oriundos dos imprevistos), destacamos os desafios práticos que consideramos importante divulgar, não como crítica, mas como alerta e contribuição a pesquisas futuras. Isso se intensifica com as alterações no cotidiano escolar, que nem sempre é um processo simples, pois impacta o social, o psicológico e o profissional, gerando transtornos e inquietações que podem até inviabilizar a realização de uma investigação na área (BORBA; PENTEADO, 2007; KENSKI, 2012; MORAN, 2003). Por outro lado, é preciso lembrar que o ofício do professor é repleto de desafios (LÜDKE; CRUZ; BOING, 2009); quando este se propõe a pesquisar sua maneira de atuar, ele deixa de ser estático e pragmático, pois, para um professor pesquisador, a sala de aula deve ser um laboratório em que cada aula busca experimentar as melhores maneiras de atingir seus alunos no processo de ensino e aprendizagem (LÜDKE, 2001).

\section{Retomada de posições}

A necessidade de investigar a integração de tecnologias no cotidiano escolar é premente, visto que cada vez mais é oferecido à sociedade um número variado de opções e novidades de recursos que por vezes podem contribuir para o processo de ensino e aprendizagem, enriquecendo o aprendizado com imagens, animações, movimentos, interações e organização, complementando os já conhecidos recursos didáticos.

$\mathrm{O}$ trabalho aqui apresentado contribui com as pesquisas sobre TDs, à medida que, por meio do acompanhamento de uma sequência de atividades, investigou a integração da realidade aumentada em dispositivos móveis no processo de ensino e aprendizagem, em específico de geometria espacial no Ensino Médio.

A observação e a análise dos resultados dos dados produzidos mostram que os desafios surgidos ao utilizar a realidade aumentada em sala de aula são de cunho de 
infraestrutura e cultural, tendo sido amenizados pela metodologia, material e estratégias desenvolvidas pelo professor pesquisador, a exemplo da utilização de equipamentos dos próprios participantes, realização das tarefas em grupos, aquisição de materiais para suprir os pontos de rede elétrica, atribuição de atividades extraclasse para instalação do aplicativo e desenvolvimento de materiais alternativos para contemplar a estudante que não quis utilizar o material da pesquisa (apesar de serem recursos já utilizados pelo professor pesquisador em sala de aula).

Mesmo com os desafios apresentados, a integração de tecnologias que envolvam dispositivos móveis pode ser possível, desde que a metodologia seja pensada de maneira flexível e focada nos objetivos de aprendizagem definidos, como evidenciado pelos participantes ao avaliar satisfatoriamente os encontros da pesquisa.

É evidente que as pesquisas em sala de aula são repletas de desafios, por possuírem realidades diferentes. Nesta pesquisa, não foram presenciados alguns dos desafios apontados na literatura, como o uso da realidade aumentada em um processo de aprendizagem que ocorra em sala de aula e em casa (NOVAL, 2013), a aplicação da realidade aumentada em outros conteúdos matemáticos (e não só a geometria) e a construção do conhecimento por parte dos estudantes por meio da autoria, tendo como apoio a realidade aumentada (OLIVEIRA, 2016).

Apresentar os desafios vivenciados em uma pesquisa é, sobretudo, dar visibilidade a importantes pontos muitas vezes esquecidos e que serão presenciados. Os problemas encarados e as soluções encontradas podem servir de alerta para os pesquisadores, evidenciando as dificuldades diárias encontradas no cotidiano escolar e da pesquisa em educação.

\section{Referências bibliográficas}

ALMEIDA, M. E. B. Tecnologia na escola: criação de redes de conhecimentos. In: ALMEIDA, M. E. B.; MORAN, J. M. (Orgs). Integração das tecnologias na educação. Secretaria de Educação a Distância. Brasília. Ministério da Educação: SEED, 2005.

AZUMA, R. A Survey of Augmented Reality - Presence: Teleoperators and Virtual environments, v. 6, n. 4.Cambridge. 1997.

BILLINGHURST, Mark. Augmented Reality in Education. New Horizons for Learning, Seattle, dezembro, 2002.

BITTAR, M. A escolha de um software educacional e a proposta pedagógica do professor: estudo de alguns exemplos da matemática. In: BELINE, W.; COSTA, N. M. L. (Orgs). Educação Matemática, tecnologia e formação de professores: algumas reflexões. Campo Mourão: FECILCAM, 2010. p. 215-242. 
BORBA, M. C; PENTEADO, M. G. Informática e Educação Matemática. 3ed. Belo Horizonte: Autêntica, 2007.

COSTA, N. M. L. D.; PRADO, M. E. B. B. A Integração das Tecnologias Digitais ao Ensino de Matemática: desafio constante no cotidiano escolar do professor. Perspectivas da Educação Matemática: Revista do programa de pós-graduação em educação matemática da universidade federal de mato grosso do sul (UFMS), Campo Grande, v. 8 n.16, p. 99-120, 2015.

DUNCAN, S. D. A. M. Uso de Técnicas de Realidade Aumentada no Ensino de Pirâmide. Dissertação (Mestrado em Matemática) - Universidade Estadual do Norte Fluminense Darcy Ribeiro. Centro de Ciência e Tecnologia. Laboratório de Ciências Matemáticas. Campos dos Goytacazes, p. 50. 2014.

FERREIRA, A. B. D. H. Novo Aurélio Século XXI. Rio de Janeiro: Nova fronteira, 1999.

GÓES, A. R. T.; GÓES, H. C. A expressão gráfica como tecnologia educacional na educação matemática - recursos didáticos para o processo de ensino-aprendizagem na Educação Básica. In: FOFONCA, E.; et al. Metodologias pedagógicas inovadoras: contextos da educação básica e da educação superior. v. 2, Curitiba: Editora IFPR, 2018. p.137-151.

KENSKI, V. M. Educação e tecnologias: O novo ritmo da informação. Campinas, SP: Papirus, 2012.

LÜDKE, M.; CRUZ, G. B. D.; BOING, L. A. A pesquisa do professor da educação. Revista Brasileira de Educação, Rio de Janeiro, v. 14, n. N.42, p. 456 - 602, Set/Dez 2009.

LÜDKE, M. O professor, seu saber e sua pesquisa. Educação \& Sociedade, Campinas: CEDES, n. 74, p. 77-96, 2001.

MACEDO, A. C.; SILVA, J. A.; BURIOL, T. M. Usando Smartphone e Realidade Aumentada para estudar Geometria espacial. RENOTE - Novas Tecnologias na Educação, Porto Alegre - RS, v. 14, n. 2, dezembro 2016.

MORAN, J. Gestão inovadora da escola com tecnologias. In: VIEIRA, A. Gestão educacional e tecnologia. São Paulo: Avercamp, 2003. p. 151-164.

NOVAL, M. D. M. Realidade Aumentada no ensino da Matemática: um caso de estudo. Dissertação (Mestrado) - Mestrado em Tecnologias da Informação e Comunicação Universidade de Trás-os-Montes e Alto Douro. Vila Real - Portugal, p. 132. 2013.

OLIVEIRA, P. S. D. Procedimentos Pedagógicos para o processo ensino aprendizagem de matemática no ensino médio: Intervenção pela Realidade Aumentada. Dissertação (Mestrado) - Programa de Pós-graduação em Ensino de Ciências: mestrado profissional - Universidade Federal de Itajubá. Itajubá - MG, p. 175. 2016.

RIBEIRO, M. W. S.; ZORZAL, E. R. Realidade Virtual e Aumentada: Aplicações e Tendências In: XIII Simpósio de Realidade Virtual e Aumentada - livro do préSimpósio 2011. Uberlândia, Brasil, 2011.

SERAFIM, M. L.; SOUSA, R. P. Multimídia na educação: o vídeo digital integrado ao contexto escolar. Campina Grande: EDUEPB, 2011.

TORI, R.; KIRNER C.; SISCOUTTO R. Fundamentos e tecnologia de realidade virtual e aumentada. Porto Alegre: SBC; 2006. 
Autores:

Alex De Cassio Macedo

Mestre do Programa de Pós-Graduação em Educação - Teoria e Prática de Ensino da UFPR da turma 2016, possui Graduação em Licenciatura Plena em Matemática pela Faculdade Estadual de Filosofia, Ciências e Letras de Paranaguá. (2004) e Especialização em Matemática Computacional aplicada à Educação no IFPR (2016). Atualmente é professor do quadro próprio do magistério-QPM do Governo do Estado do Paraná no Colégio Estadual Gratulino de Freitas. Proflecao@gmail.com

Anderson Roges Teixeira Góes Universidade Federal do Paraná - UFPR Doutor em Métodos Numéricos em Engenharia Programa de Pós-graduação em Educação em Ciências e em Matemática; Programa de Pós-graduação em Educação: Teoria e Prática de Ensino Educação Matemática: Tecnologias Educacionais; Tecnologia Assistiva; Educação Inclusiva; Desenho Universal para Aprendizagem. artgoes@ufpr.br 